\title{
Low Levels of Vitamin D correlate with Hemoglobin A1c and Interleukin-10 Levels in Pediatric Type 1 Diabetes Mellitus Patients
}

Desy Wulandari ${ }^{1^{*}}$, Haryudi A. Cahyono ${ }^{2}$, Edi Widjajanto ${ }^{3}$, Anik Puryatni ${ }^{4}$

\author{
${ }^{1}$ Department of Child Health Faculty of Medicine Brawijaya University/Saiful Anwar Hospital, Malang, 65145, Indonesia \\ ${ }^{2}$ Endocrinology Division, Department of Child Health Faculty of Medicine Brawijaya University/Saiful Anwar Hospital, \\ Malang, 65145, Indonesia \\ ${ }^{3}$ Department of Clinical Pathology Faculty of Medicine, Brawijaya University, Malang, 65145, Indonesia \\ ${ }^{4}$ Nutrition and Metabolic Diseases Division, Department of Child Health Faculty of Medicine Brawijaya University/Saiful Anwar \\ Hospital, Malang, 65145, Indonesia
}

\begin{abstract}
Vitamin D is reported to affect immune system and prevent autoimmunity. Some studies show that low vitamin D levels in patients with type 1 diabetes are associated with glycemic control and inflammatory status. The study was cross sectional design with subjects T1DM patients aged 1-18 years, and healthy subjects with similar age. Plasma levels of vitamin D (25(OH)D3) was measured using ELISA. Glycemic control measured by hemoglobin A1c (HbA1c). Inflammatory status measured by examination of IL-10 using ELISA method. Comparison of vitamin D levels, HbA1c levels and IL-10 levels were analyzed by independent samples t-test. The relationship between vitamin D levels, HbA1c, and IL-10 were analyzed by Pearson's correlation. Our subjects were 20 T1DM patients and 20 healthy controls. Our study showed that vitamin D $(25(\mathrm{OH}) \mathrm{D} 3)$ levels was significantly lower than in healthy controls $(20.82 \pm 5.53 \mathrm{ng} / \mathrm{ml}$ vs $33.14 \pm 2.17 \mathrm{ng} / \mathrm{ml} ; \mathrm{p}=0.000)$, HbA1c levels was significantly higher than in healthy controls $(10.08 \pm 5.02 \%$ vs $5.02 \pm 0.18 \%$; $p=0.000)$, IL-10 levels was significantly lower than in healthy controls $(16.50 \pm 4.57 \mathrm{ng} / \mathrm{ml}$ vs $73.52 \pm 7.11 \mathrm{ng} / \mathrm{ml} ; \mathrm{p}=0.000)$. Vitamin D levels were correlated with HbA1c $(p=0.000 ; r=-0.871)$, correlated with IL-10 ( $p=0.000 ; r=0.853)$. HbA1c levels were correlated with IL-10 levels $(p=0.000 ; r=-0.878)$. Low vitamin D levels are common in T1DM patients. There were significant differences in vitamin D levels, IL-10, and HbA1c among T1DM patients compared to normal subjects. Vitamin D levels were associated with HbA1c levels and IL-10 levels in T1DM.
\end{abstract}

Keywords: $H b A 1 c$, interleukin 10, vitamin $D$, type 1 diabetes mellitus

\section{INTRODUCTION}

Type 1 diabetes results from autoimmune destruction of insulin-producing $\beta$ cells in the islets of the pancreas [1]. Failure mechanisms of immunoregulator cause autoreactive $\mathrm{T}$ cells, inflammatory process in the islets and damage the pancreatic $\beta$ cell $[2,3]$. Vitamin $\mathrm{D}$ deficiency may increase the risk of developing autoimmune diseases including type 1 diabetes mellitus. This occurs due to loss of modulation of vitamin $\mathrm{D}$ on the immune system and inflammatory reactions in diabetes [4]. The role of vitamin $\mathrm{D}$ as an immunomodulator can be explained by several mechanisms that

\footnotetext{
*Corresponding author:

Desy Wulandari

Department of Child Health Faculty of Medicine Brawijaya University/Saiful Anwar Hospital, Malang, 65145, Indonesia E-mail: deardesy@yahoo.com
}

vitamin $\mathrm{D}$ plays a role in dendritic cells that play a central role in the immune response mediated $\mathrm{T}$ cells activation, modifying $\mathrm{T}$ cell differentiation, induce the secretion of cytokines, which decrease the secretion of pro-inflammatory cytokines such as interleukin-12 (IL12) and increased anti-inflammatory cytokines such as interleukin-10 (IL-10). Vitamin D also acts directly on $\mathrm{T}$ cells to promote IL-10 secreting Tregs. IL-10 is an anti inflammatory cytokine that has the potential downregulation activity of the inflammatory process $[5,6]$.

Indonesia is a tropical climate country where Indonesian people will not come through vitamin D deficiency [7]. When there is a relationship between vitamin D deficiency and glycemic control of type 1 diabetes mellitus, Indonesian children should have good glycemic control, whereas today they found poor 
glycemic control [8]. Therefore the aim of this study was to determine the relationship between vitamin $\mathrm{D}$ levels with HbA1c level and IL-10 level in T1DM.

\section{MATERIALS AND METHODS}

This cross sectional study was conducted in T1DM children attending the Pediatric Endocrinology Clinic, Department of Pediatrics, Saiful Anwar Hospital Malang from January to March 2014. Twenty children with established T1DM and 20 healthy subject matched age were recruited as controls. The study was approved by the ethics committee of Brawijaya University School of Medicine, Saiful Anwar Hospital Malang, Indonesia and informed consent was obtained from all participants. Diabetic children with impairment of liver function, renal function, anemia, infection, other autoimmune disease or those on vitamin $\mathrm{D}$ supplementation were excluded. Likewise, healthy children who were on vitamin D were excluded. All patients underwent baseline investigation for hematologic and biochemical laboratory parameters.

\section{Vitamin $D$ measurement}

Vitamin D (25(OH)D3) level was assesed using Enzyme Linked Immunosorbent Assay in accordance with the manufacturer's instruction (Orgentec, Alegria, Germany). The Alegria ${ }^{\circledR}$ assay features barcoded 8-wellmicrostrips, called Alegria ${ }^{\circledR}$ Test Strips. Each strip is designed for a single determination of one patient sample. The Alegria ${ }^{\circledR}$ Test Strip holds a complete set of reagents. Included are enzyme conjugate, enzyme substrate, sample buffer and a test specific control. Two wells of the Alegria ${ }^{\circledR}$ Test Strip are coated with a 25$\mathrm{OH}$ vitamin $\mathrm{D} 3 / \mathrm{D} 2$ antibody and serve as reaction wells for one control and one patient sample. Two more wells of the Alegria ${ }^{\circledR}$ Test Strip are coated with a $25-\mathrm{OH}$ vitamin D tracer or a $25-\mathrm{OH}$ vitamin D control respectively. The determination is based on a competitive enzyme linked immunosorbent assay (ELISA) with the following steps: The sample is pipetted into well No 1. Inside the Alegria ${ }^{\circledR}$ Random Access Analyser the sample is mixed with tracer reagent and the $25-\mathrm{OH}$ vitamin $\mathrm{D} 3 / \mathrm{D} 2$ is delivered from vitamin $\mathrm{D}$ binding protein. 25- $\mathrm{OH}$ vitamin $\mathrm{D}$ and tracer reagent coated in well No 2 are suspended with buffer. Sample and control are then transferred to the reaction wells No 3 and No 4 where 25-OH vitamin D3/D2 and 25- $\mathrm{OH}$ vitamin $\mathrm{D}$ tracer reagent compete for binding to the coated $25-\mathrm{OH}$ vitamin $\mathrm{D} 3 / \mathrm{D} 2$ antibody. Complexes are formed between 25-OH vitamin D3/D2 and antibody or $25-\mathrm{OH}$ vitamin $\mathrm{D}$ tracer reagent and antibody. After incubation, a first washing step removes unbound and unspecifically bound molecules. Subsequently added enzyme conjugate binds to the immobilized tracer-antibody complexes. After incubation, a second washing step removes unbound enzyme conjugate. Addition of enzyme substrate solution results in hydrolisation and color development during incubation. The intensity of the blue color can be measured photometrically at 650 $\mathrm{nm}$. Vitamin D insufficiency defined as a level 20-30 $\mathrm{ng} / \mathrm{ml}$, vitamin $\mathrm{D}$ deficiency as level $<20 \mathrm{ng} / \mathrm{ml}$, whereas normo vitamin $\mathrm{D}$ as level $>30 \mathrm{ng} / \mathrm{ml}$ [9].

\section{HBA1c measurement}

HbA1c level was assesed by BioRad D-10. Program utilizes principles of ion exchange high performance liquid chromatography (HPLC). The samples are automatically diluted on the D-10 and injected into

Table 1. Characteristics of T1DM patients and healthy children groups

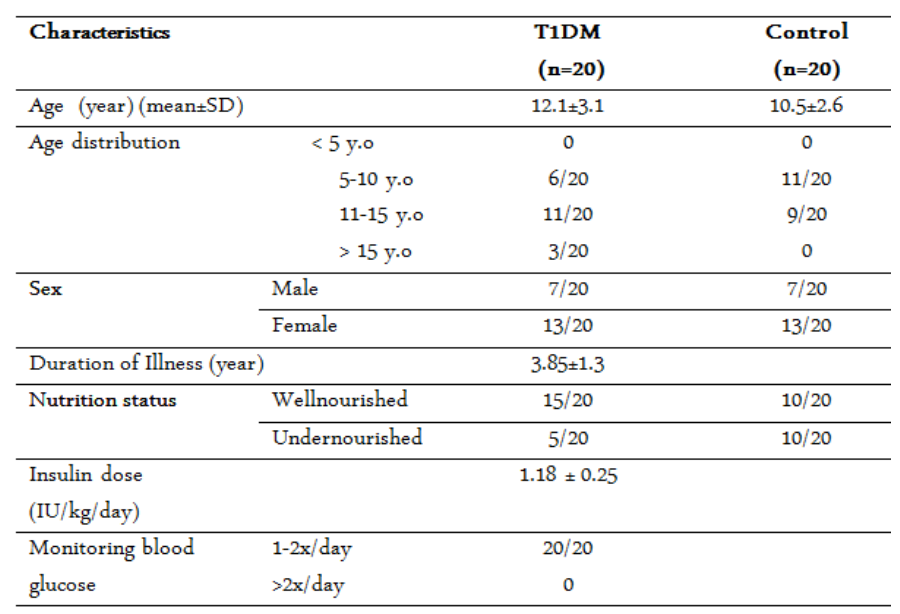


Table 2. Laboratory results of T1DM patients compare to healthy children groups

\begin{tabular}{|c|c|c|c|c|c|c|c|}
\hline \multirow{2}{*}{\multicolumn{2}{|c|}{ Laboratory Results }} & \multicolumn{3}{|c|}{ T1DM $(n=20)$} & \multicolumn{3}{|c|}{ Control (n=20) } \\
\hline & & $\mathbf{n}$ & meantSD & range & $\mathbf{n}$ & meantSD & range \\
\hline \multicolumn{2}{|c|}{ Hemoglobin $(\mathrm{g} / \mathrm{dl})$} & & $12.19 \pm 0.55$ & $11.5-13.5$ & & $12.48 \pm 0.55$ & $12-14$ \\
\hline \multicolumn{2}{|c|}{ Leucocytes $(\mathrm{g} / \mathrm{dl})$} & & $8925 \pm 528.57$ & $7960-9870$ & & $7871 \pm 1151$ & $5100-9420$ \\
\hline \multirow{2}{*}{\multicolumn{2}{|c|}{ Trombocytes (g/dl) }} & & $347250 \pm 27082$ & $301.000-$ & & $312650 \pm 29805$ & $275000-$ \\
\hline & & & & 392.000 & & & 394000 \\
\hline \multicolumn{2}{|c|}{ Ureum (mg/dl) } & & $24.24 \pm 3.87$ & $18-29.1$ & & $24.32 \pm 3.26$ & $20.1-30.2$ \\
\hline \multicolumn{2}{|c|}{ Creatinin (mg/dl) } & & $0.6 \pm 0.1$ & $0.4-0.9$ & & $0.59 \pm 0.1$ & $0.3-0.8$ \\
\hline \multicolumn{2}{|c|}{ ALT (U/L) } & & $30.35 \div 3.15$ & $23-39$ & & $29.45 \pm 2.9$ & $24-35$ \\
\hline \multicolumn{2}{|c|}{ AST (U/L) } & & $30.65 \pm 2.11$ & $27-36$ & & $31.85+3.06$ & $27-39$ \\
\hline \multicolumn{2}{|c|}{ HbA1c (\%) } & & $10.08 \pm 2.28$ & $7-14.5$ & & $5.02 \pm 0.18$ & $4.7-5.4$ \\
\hline \multicolumn{2}{|c|}{$<6.5$} & $0 / 20$ & & & & & \\
\hline \multicolumn{2}{|c|}{$6.5-7.6$} & $3 / 20$ & & & & & \\
\hline \multicolumn{2}{|c|}{$7.6-9$} & $3 / 20$ & & & & & \\
\hline \multicolumn{2}{|c|}{$>9$} & $14 / 20$ & & & & & \\
\hline \multirow{3}{*}{$\begin{array}{l}\text { Vitamin } \\
\mathrm{D} \\
(\mathrm{ng} / \mathrm{ml})\end{array}$} & Deficiency & $12 / 20$ & $17.3 \pm 2.59$ & $11.9-19.8$ & $0 / 20$ & - & \\
\hline & Insufficient & $6 / 20$ & $24.35 \pm 3.63$ & $20.3-29.4$ & $0 / 20$ & - & \\
\hline & Normal & $2 / 20$ & $31.3 \pm 0.7$ & $30.8-31.8$ & $20 / 20$ & $33.14 \pm 2.17$ & $30.4-38.3$ \\
\hline \multicolumn{2}{|c|}{ IL-10 (pg/ml) } & & $16.5 \pm 4.57$ & $7.8-24.5$ & & $73.52 \pm 7.11$ & $64.6-88.7$ \\
\hline
\end{tabular}

Table 3. Comparison of vitamin D (25(OH)D3), HbA1c, IL-10 between type 1 DM to healthy children

\begin{tabular}{lccc}
\hline & T1DM & Control & P \\
\hline $25(\mathrm{OH}) \mathrm{D}_{3}(\mathrm{ng} / \mathrm{ml})$ & $20.82 \pm 5.53$ & $33.14 \pm 2.17$ & 0.000 \\
\hline $\mathrm{HbA1c}(\%)$ & $10.08 \pm 5.02$ & $5.02 \pm 0.18$ & 0.000 \\
\hline $\mathrm{IL}-10(\mathrm{pg} / \mathrm{ml})$ & $16.50 \pm 4.57$ & $73.52 \pm 7.11$ & 0.000 \\
\hline
\end{tabular}

the analytical cartridge. The D-10 delivers a programmed buffer gradient of increasing ionic strength to the cartridge, where the hemoglobins are separated based on their ionic interactions with cartridge material. If there is less than $2 \mathrm{ml}$ of sample in the tube, then the sample must be prediluted. Before pipetting, thoroughly mix the sample by gently inverting the tube. To predilute, pipet $1.5 \mathrm{ml}$ of wash/ diluent solution into a labeled $1.5 \mathrm{ml}$ vial, followed by $5 \mu \mathrm{L}$ of the whole blood sample. Cap the sample vial and mix thoroughly. The separated hemoglobins then pass through the flow cell of the filter photometer, where changes in the absorbance at $415 \mathrm{~nm}$ are measured.

\section{IL-10 measurement}

Levels of IL-10 were measured using Human IL10 Quantikine ELISA kits according to the R\&D Systems (Minneapolis, MN, USA) manufacturer's instructions. This assay employs the quantitative sandwich enzyme immunoassay technique. A monoclonal antibody specific for IL-10 has been pre-coated onto a microplate. Standards and samples are pipetted into the wells and any IL-10 present is bound by the immobilized antibody. After washing away any unbound substances, an enzyme-linked monoclonal antibody spe- cific for IL-10 is added to the wells. Following a wash to remove any unbound antibody-enzyme reagent, a substrate solution is added to the wells and color develops in proportion to the amount of IL-10 bound in the initial step. The color development is stopped and the intensity of the color is measured. Samples were analyzed and compared with control samples.

\section{Statistical analysis}

The results were analyzed using appropriate statistical tests on Statistical Package for Social Sciences (SPSS) software. Quantitative data was expressed as mean \pm 2 standard deviation (SD). Statistical significance of quantitative variables between different categories was analysed using independent sample t-test. Pearson's correlation coefficient $(r)$ was used to indicate significant linear relationship among quantitative variables. A p value $<0.05$ was considered as significant.

\section{RESULTS AND DISCUSSION}

Of the total number of children surveyed, 13 T1DM and 13 of the healthy children were females. The mean age for diabetics versus controls was $12.1 \pm 3.1$ years versus $10.5 \pm 2.6$ years (Table 1 ).

The result of hematological and biochemical labora- 
tory measurement are shown in table 2 . From the laboratory results showed high levels of HbA1c $(10.08 \pm 2.28)$, 14 out of 20 had poor metabolic control (HbA1c > 9\%), 12 T1DM patients with vitamin D deficiency, 6 patients with vitamin D insufficiency, and 2 patients with normal level of vitamin $\mathrm{D}$, other result of hematological and biochemical parameters showed as normal level.

Mean of vitamin D $(25(\mathrm{OH}) \mathrm{D} 3)$ level was $33.14 \pm 2.17 \mathrm{ng} / \mathrm{ml}$ in the normal control, and $20.82 \pm 5.53$ in T1DM group $(\mathrm{p}=0.000)$ (table 3$)$. Mean HbA1c level was $5.02 \pm 0.18 \%$ in the normal control, and $10.08 \pm 5.02$ in T1DM group $(\mathrm{p}=0.000)$ (table 3$)$. Mean IL-10 level was $73.52 \pm 7.11 \mathrm{pg} / \mathrm{ml}$ in the normal control, and $16.50 \pm 4.57$ in T1DM group $(\mathrm{p}=0.000)$ (table 3). There was correlation between 25(OH)D3 level and HbA1c level ( $p=0.000 ; r=-0.871)$, IL-10 level $(\mathrm{p}=0.000 ; \mathrm{r}=0.853)$. HbA1c levels in patients T1DM was correlated with levels of IL-10 ( $\mathrm{p} 0.000 ; \mathrm{r}=-0.878$ ).

This is consistent with previous epidemiological data with peak incidence occurs during puberty [10]. Based on the sex distribution was found that most females (13 out of 20). The incidence of type $1 \mathrm{DM}$ in Indonesia with a sex ratio of female than male 45:55 [11]. The mean insulin dose used in our study was $1.18 \pm 0.25$. In contrast to the study by Batubara et al11

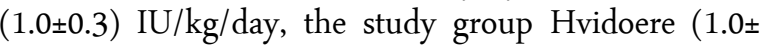
$0.3) \mathrm{IU} / \mathrm{kg} /$ day [12]. HbA1c levels $\left(\mathrm{HbA} 1 \mathrm{c}=10.08_{ \pm}\right.$ 2.28) was showed poor metabolic control. This is similar to research in Tanzania obtained with a mean HbA1c levels were still high (12.6 $\pm 3.5 \%) 13$, similarly a study done in Sudan where Elamin et al. found a high incidence of poor glycemic control estimated by HbA1c [14]. Most likely the underlying cause is the association between limited insulin supply and lack of self-monitoring of blood glucose. Furthermore, in addition to limited insulin supply, patients reduce their insulin dose to ensure longer periods of insulin treatment. Nevertheless, insulin storage might also influence the effect of the insulin, as many families store the insulin in a pot with cold water, exposing the insulin to high temperatures. Storage of insulin may influence the effects of insulin. Insulin must never be frozen. Direct sunlight or warming (in hot climates) damages insulin. Patients should not use insulins that have changed in appearance (clumping, frosting, precipitation, or discolouration). Unused insulin should be stored in a refrigerator (4-8 oC). After first usage, an insulin vial should be discarded after 3 months if kept at 2-8 $0 \mathrm{C}$ or 4 weeks if kept at room temperature. However, for some insulin preparations, manufacturers recommend only 10-14 days of use in room temperature [13-15].

Vitamin D levels of T1DM patients was significantly lower than healthy controls $(\mathrm{p}=0.000)$. Of the 20 subjects of T1DM, 12 out of 20 with a deficiency of vitamin D, 6 out of 20 vitamin D insufficiency, and 2 out of 20 with normal levels, whereas all subject in the control group with normal vitamin D levels. Our study similar with study in Switzerland, in a cross-sectional study, $60-84 \%$ of T1DM were 25(OH)D3 deficient [16]. In Qatar, in a case control study, $90.6 \%$ of T1DM children versus $85.3 \%$ of nondiabetic children had vitamin D deficiency [17]. Similarly, in North India in a case-control study, $58 \%$ of T1DM and only $32 \%$ of controls had 25(OH)D3 deficiency [18]. In Northeastern US, in a cross-sectional study, it has been found that $15 \%$ of $\mathrm{T} 1 \mathrm{DM}$ patients were $25(\mathrm{OH}) \mathrm{D} 3$ deficient and $61 \%$ were insufficient, findings inversely associated with age Low vitamin $\mathrm{D}$ levels in type 1 diabetes is likely to be influenced by immunomodulatory system [19]. Immunomodulatory functions of vitamin D is the ability to inhibit the expression of Th1 cytokines, enhance the role of Th2 cytokines through directly act on $\mathrm{T}$ cells or indirectly through APCs [20]. Vitamin D affects Th cell polarization by inhibiting Th1 (IFN- $\gamma$ production) and augmenting Th2 cell development (IL-4, IL-5, and IL-10 production). Vitamin D acts directly on Th cells and can, in the absence of APC, enhance the development of a Th2 phenotype and augment the expression of the transcription factors c-maf and GATA-3 [21,22].

There are significant differences in HbA1c levels in T1DM compared to controls and also significant negative correlation between HbA1c levels T1DM and levels of vitamin D. High HbA1c levels indicate poor glycemic control. A study in the United States had average high $\mathrm{HbA1c}$ levels $(9.3 \pm 1.9 \%)$ in T1DM with vitamin D deficiency. Vitamin D status is one of the factors associated with glycemic control in children and adolescents with T1DM.19 VDR (Vitamin D Receptor) found on pancreatic beta cells, suggesting its role in glycemic control. Vitamin D inhibits inflammatory cytokine that is involved in beta cell destruction. Research by Magee and colleagues examined the association between vitamin $\mathrm{D}$ and glycemic control, measured by $\mathrm{HbA} 1 \mathrm{c}$ in type 1 diabetes in the pediatric population [23].

There are significant differences in the levels of IL10 in T1DM compared with controls and significant positive correlation between the levels of IL-10 T1DM and levels of vitamin D. Our research is similar with in 
vitro studies in Turkey whereas levels of IL-10 were lower compared to the control group $(\mathrm{p}=0.033)$ [24]. IL-10 may provide an important part of the anti inflammatory properties by inhibiting the transcription factor. IL-10 is able to inhibit the nuclear translocation of NF-kB heterodimer. 1,25(OH)2D3 can increase NF$\mathrm{kB}$ inhibitor (IkB- $\alpha$ ) by increasing mRNA stability and decreasing the phosphorylation of $I k B-\alpha$. The increase in IkB- $\alpha$ levels reduces nuclear translocation of NF-kB and thereby downgrades its activity $[25,26]$.

There was a significant negative correlation between HbA1c levels and the levels of IL-10. IL-10 was also significantly associated with $\mathrm{HbA1c}$ from a study performed by Sawa [27]. IL-10 pathway is reportedly working on phosphatidylinositol 3-kinase (PI3K) which is responsible for insulin action on glucose uptake and suppression of gluconeogenesis [27,28].

\section{CONCLUSIONS}

In conclusion, the present study revealed that vitamin $\mathrm{D}$ deficiency was higher in diabetic children compared to healthy controls. It will be of interest for future studies to investigate whether vitamin D supplementation will improve glycemic control and inflammation status in vitamin $\mathrm{D}$ deficient diabetic children.

\section{ACKNOWLEDGMENT}

We would like to thank the Department of Child Health, Faculty of Medicine, University of Brawijaya/ dr.Saiful Anwar General Hospital, Malang, Indonesia for providing the grant to accomplish this research. We also thank to Ajeng S.Si from Pathology Clinics Saiful Anwar General Hospital, and Satuman MSi, from Faal Laboratory of Medical Faculty, Brawijaya University for their good assistance in this research.

\section{REFERENCES}

1. Achenbach P, Bonifacio E, Koczwara K, Ziegler AG (2005) Natural history of type 1 diabetes. Diabetes. 54(2): 25-31.

2. Rabinovitch A (2004) Roles of Cell-Mediated Immunity and Cytokines in the Pathogenesis of Type 1 Diabetes Mellitus. Diabetes Mellitus: A Fundamental and Clinical Text 3rd Edition. Philadelphia: Lippincott Williams \& Wilkins. 520-525.

3. Zoka A, Muzes G, Somogyi A, Varga T, Szeman B, Hadarits O, Firneisz G (2013) Altered Immune Regulation in Type 1 Diabetes. Clin Dev Immunol. 254874: 1-17.

4. Mathieu C (2011) Vitamin D and the Immune System:
Getting It Right. International Bone \& Mineral Society. 8: 178-186.

5. Mathieu C, Gysemans C, Giulietti A, Bouillon R (2005) Vitamin D and diabetes. Diabetologia. 48(7): 1247-57.

6. Bouillon R, Geert C, Lieve V, Evelyne VE, Annemieke V, Hilary FL (2008) Vitamin D and Human Health: Lessons from Vitamin D Receptor Null Mice. Endocr Rev. 29(6): 726-776.

7. Handono K, Puspitasari L, Rudijanto A, Wahono S, Kalim H (2013) Vitamin D Serum Level And Disease Activity In Patients With Systemic Lupus Erythematosus. International Journal of Pharmaceutical Science Invention. 2(2): 35-40.

8. Cahyono HA (2011) Gambaran Klinis dan Laboratoris Diabetes Melitus Tipe 1 pada Anak. Jurnal Kedokteran Brawijaya. 26(4): 195-198.

9. Holick MF (2007) Vitamin D deficiency. N Engl J Med. 357(3): 266-81.

10. Soltesz G, Patterson CC, Dahlquist G (2007) Worldwide childhood type 1 diabetes incidence-what can we learn from epidemiology?. Pediatric Diabetes. 8(6): 6-14.

11. Batubara JRL (2002) Audit of childhood diabetes control in Indonesia. Paediatrica Indonesiana. 42(11-12): 280-286.

12. De Beaufort CE, Swift PGF, Skinner CT, Aanstoot HJ, Aman J, Cameron F (2007) The Hvidoere study group on childhood diabetes. Continuing stability of cener differences in pediatric diabetes care : Do advances in diabetes treatment improve outcome?. Diabetes Care. 9: 2245-50.

13. Majaliwa ES, Munubhi E, Ramaiya K, Mpembeni R, Sanyiwa A, Mohn A, Chiarelli F (2007) Survey on Acute and Chronic Complications in Children and Adolescents with Type 1 Diabetes at Muhimbili National Hospital in Dar es Salaam, Tanzania. Diabetes Care. 30(9): 2187-92.

14. Elamin A, Hussein O, Tuvemo T (2006) Growth, puberty and final height in children with Type 1 diabetes. J Diabetes Complications. 20(4): 252-6.

15. ISPAD (2011) Diabetes in Childhood and adolescence. ISPAD Clinical Practice Consensus Guidelines. p 61

16. Janner M, Ballinari P, Mullis PE, Flick CE (2010) High prevalence of vitamin D deficiency in children and adolescent with type 1 diabetes. Swiss Med Wkly. 140(7): 1-6.

17. Bener A, Alsaied A, Al-Ali M, Al-Kubaisi A, Basha B, Abraham A, Guiter G, Mian M (2009) High prevalence of vitamin $\mathrm{D}$ deficiency in type 1 diabetes mellitus and healthy children. Acta Diabetologica. 46: 183-9.

18. Borkar VV, Devidayal VS, Bhalla AK (2010) Low levels of vitamin D in North Indian children with newly diagnosed type 1 diabetes. Pediatric Diabetes. 11(5): 345-50.

19. Svoren BM, Volkening LK, Wood JR, Laffel LMB (2009) Significant vitamin D deficiency in youth with type 1 diabetes mellitus. J of Peds. 154(1): 132-134. 